\title{
ASSOCIATION OF ABO BLOOD GROUP AND BREAST CANCER- A RETROSPECTIVE STUDY IN ERBIL CITY
}

Samir Anwar Jabbar', Nooraddin Ismail²

1Trainee, Department of General Surgery, Kurdistan Board of Medical Specialties, Erbil, Kurdistan Region, Iraq.

2Professor and HOD, Department of General Surgery, Hawler Medical University, Erbil, Kurdistan Region, Iraq.

\section{BACKGROUND}

\section{ABSTRACT}

Different studies have been done worldwide to identify possible relationships, if any, between ABO blood group and breast cancer. They have concluded with different results.

The aim of this study was to identify possible association, if any, between ABO blood group and breast cancer.

\section{MATERIALS AND METHODS}

This is a cross-sectional study carried out in Erbil city, Kurdistan Region of Iraq over a period from November 2017 - May 2018. One hundred and twenty-two cases were included in this study. Data regarding patients' case sheet number, age, blood group and $\mathrm{Rh}$ factor were collected from the patients' case sheet and entered into the computer and then analysis was done.

\section{RESULTS}

The mean age group in our study was $48.42 \pm 10.27$ years. Our study showed highest association between Blood Group 0 and breast cancer, which was (50.8\%) and the $\mathrm{P}$ was $<0.01$.

\section{CONCLUSION}

The present study revealed high association between Blood Group 0 and breast cancer.

\section{KEY WORDS}

ABO Blood Group; Rh; Breast Cancer.

HOW TO CITE THIS ARTICLE: Jabbar SA, Ismail N. Association of ABO blood group and breast cancer- a retrospective study in Erbil city. J. Evolution Med. Dent. Sci. 2018;7(37):4106-4108, DOI: 10.14260/jemds/2018/918

\section{BACKGROUND}

A high number of breast cancer cases are diagnosed every year. ${ }^{1}$ Breast cancer is a worldwide malignant disease. Over one million new cases of breast cancers are diagnosed every year. ${ }^{2}$ Although, there are several other factors having the risk of breast cancer, but ABO blood groups also have been associated with risk and survival of several malignancies including pancreatic cancer ${ }^{3}$ and stomach cancer. ${ }^{4}$ Initially, the association was found between stomach cancer and Blood Group A. Breast cancer is a multifactorial cancer. Established risk factors include a family history of breast cancer, age of menarche, age of first birth, duration of lactation, parity, age of menopause, total lifetime ovulations, diet and hormonal levels. ${ }^{5-7}$ One of the major antigens in humans is the blood group antigens that are present on the surface of the blood cells and different epithelial cells and alteration of these blood group antigens is associated with cancer.8,9 Therefore, blood group antigens on the surface of cancer cells can be used as useful prognostic and diagnostic markers in different types of human cancers. ${ }^{10,11}$

Some studies report found no association between blood group and breast cancer risk. ${ }^{12-16}$ However, others suggest there are associations. ${ }^{17}$ Our aim in this study was to evaluate the possible relationships between $\mathrm{ABO}$ blood group and risk of breast cancer.

'Financial or Other Competing Interest': None.

Submission 12-08-2018, Peer Review 28-08-2018,

Acceptance 31-08-2018, Published 10-09-2018.

Corresponding Author:

Samir Anwar Jabbar,

Iraq, Kurdistan Region, Erbil, Iraq.

E-mail: samir.barznjy@gmail.com

DOI: $10.14260 /$ jemds $/ 2018 / 918$

\section{MATERIALS AND METHODS}

This research was conducted on an analytical base (retrospective hospital-based study). From November 2017 to May 2018, confirmed breast cancer cases were included in this study. 122 affected women with breast cancer who have documents in Erbil Breast Centre, which is located in Erbil city were studied to find out any possible associations between breast cancer and ABO blood group and to know the frequency of each blood group in relation to breast cancer. The data including age, confirmed laboratory investigations and the file codes were taken from the patient's case sheet. The data were entered into the computer and analyses of percentages were done. This study has been done after admitting ethical approval letter to the Local Ethics Committee of Kurdistan Board for Medical Specialties (KBMS).

\section{Inclusion Criteria}

- Female breast cancer.

- Confirmed pathology.

- Detailed case history report.

\section{Exclusion Criteria}

Patients with insufficient data sheet information have been excluded.

Data was analysed using the Statistical Package for Social Sciences (SPSS, version 22). Frequency or median values were given as descriptive statistics. Fisher's test was used to determine differences in proportions. Mann-Whitney $\mathrm{U}$ test was used to compare variables. A p-value of $\leq 0.05$ was considered statistically significant. 


\section{RESULTS}

The total number of the studied sample was 122 women affected with breast cancer. Their mean age \pm SD was $48.42 \pm 10.27$ years, ranging from 27 to 78 years. The median was 47.5 years. The largest proportion $(39.3 \%)$ was in the age group of $40-49$ years, as presented in Table 1 . Around half $(50.8 \%)$ of the samples were of Blood Group ' 0 ', $21.3 \%$ were of Group 'A', $16.4 \%$ were of Group 'B' and $11.5 \%$ were of Group 'AB' (Figure 1).

\begin{tabular}{|c|c|c|}
\hline Age (Years) & No. & $(\mathbf{0 )}$ \\
\hline$<40$ & 23 & $(18.9)$ \\
\hline $40-49$ & 48 & $(39.3)$ \\
\hline $50-59$ & 33 & $(27.0)$ \\
\hline$\geq 60$ & 18 & $(14.8)$ \\
\hline Total & $\mathbf{1 2 2}$ & $\mathbf{( 1 0 0 . 0 )}$ \\
\hline \multicolumn{2}{|c|}{ Table 1. Distribution of Sample by Age } \\
\hline
\end{tabular}

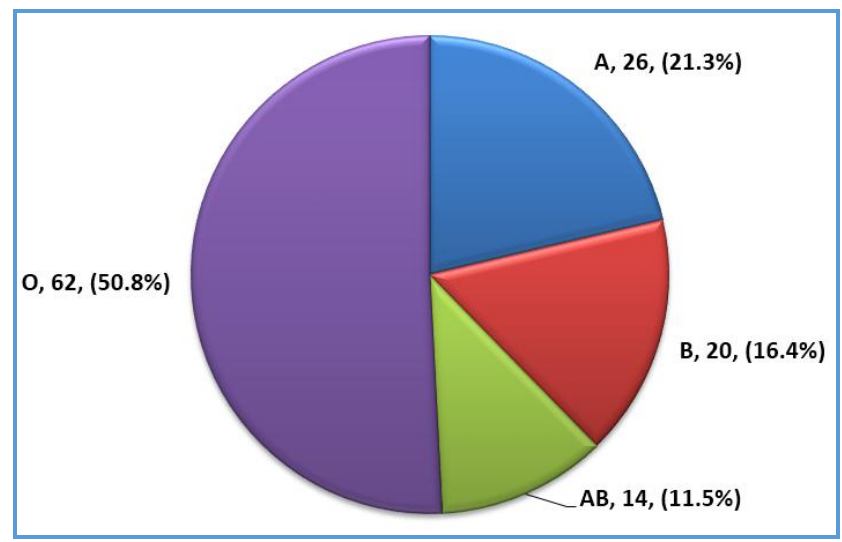

Figure 1. Distribution of Sample by ABO Blood Groups

Results showed that $86.1 \%$ were $\mathrm{Rh}$ positive and the rest $(13.9 \%)$ were of Rh negative. The details presented in Table 2 show that out of the 122 breast cancer cases, $1.69 \%$ are in Group A-, 19.7\% in Group A+, 1.6\% in Group AB-, 9.8\% in Group $\mathrm{AB}+, 2.5 \%$ in Group B-, $13.9 \%$ in Group B+, $8.2 \%$ in Group 0-, and $42.6 \%$ in Group 0+.

\begin{tabular}{|c|c|c|}
\hline Blood Groups & No. & (\%) \\
\hline A- & 2 & (1.6) \\
\hline$A+$ & 24 & (19.7) \\
\hline AB- & 2 & $(1.6)$ \\
\hline $\mathrm{AB}+$ & 12 & (9.8) \\
\hline B- & 3 & $(2.5)$ \\
\hline $\mathrm{B}+$ & 17 & (13.9) \\
\hline $0-$ & 10 & $(8.2)$ \\
\hline $0+$ & 52 & $(42.6)$ \\
\hline Total & 122 & $(100.0)$ \\
\hline \multicolumn{3}{|c|}{ Table 2. Distribution of Sample by Blood Groups } \\
\hline
\end{tabular}

\section{DISCUSSION}

High frequency with Blood Group $\mathrm{O}$ had been discovered among breast cancer patients in our study. A significant Pvalue was found in this study.

This was also proved by other studies. A study showed positive relation between Blood Group 0 and breast cancer. 18 Another study also reported that Blood Group 0 had a high risk of breast cancer. ${ }^{19}$ Another study has shown that Blood Group 0 has the second highest risk with breast cancer after Blood Group A. ${ }^{20}$ Moreover, another study by Satyanam
Bhartiya et $\mathrm{al}^{21}$ shows higher frequency of association between Blood Group AB and breast cancer.

In contrast, a study has shown that women with Blood Group 0 have some protection against breast cancer. ${ }^{22}$

We have some other inconsistent studies. For instance, a study by Guleria showed significant association between Blood Group A and breast cancer. ${ }^{23}$ Another study reported by Mourali shows a slight increased risk of breast cancer diagnosis in Blood Group A. ${ }^{24}$

On the other hand, there are also other contradictory studies which show different results. Surekha et al have discovered that Blood Group B has highest incidence with breast cancer. 25

In contrast to all the above-mentioned studies, there are other different ones that show no significant relation between ABO blood group and breast cancer, Jayant K.26 Also. Dede et $\mathrm{al}^{27}$ and Stamatakos et al ${ }^{17}$ did not find such an association between blood groups and breast cancer.

A meta-analysis of 9665 breast cancer patients and 2,44,768 controls by Su-Yu MIAO et al that reviewed 14 studies in 2011 in many countries showed that ABO blood types had no association with breast cancer risk. ${ }^{19}$ Apart from this, other studies have also observed no association between $\mathrm{ABO}$ blood group and breast cancer. ${ }^{28}$

In this regard, relevant studies have reported inconsistent results. For example, blood group and breast cancer were reported to have no correlation by Jayant $\mathrm{K}$ [11], while Surekha et al [29] concluded that breast cancer was more prevalent among individuals with blood group B. The tumour marker expressed by breast and stomach cancer cells is called Thomsen-Friedenrich antigen (T) and its precursor (Tn) which in healthy individuals are defeated and masked by the immune system. However, when a cell becomes malignant, the immune system can have access to them. There is a structural similarity between these markers and $\mathrm{A}$ antigen because terminal sugar $\mathrm{N}$-acetylgalactosamine is shared by it [30]. Individuals with group A blood; therefore, give the least aggressive antibody response to these cancer cells, leading to poor outcomes [31].

\section{CONCLUSION}

Our study showed highest association between Blood Group 0 and breast cancer. There are controversies about possible relationship or association between ABO Blood Group and breast cancer.

Further researches and studies in large series are needed to discover or elucidate the relationship between $\mathrm{ABO}$ blood group and breast cancer.

\section{ACKNOWLEDGEMENTS}

We would like to acknowledge the Erbil Breast Centre management team, the active volunteers and all the colleagues who helped us conducting this study.

\section{REFERENCES}

[1] Fletcher SW. Breast cancer screening: a 35-year perspective. Epidemiologic Reviews 2011;33(1):16575.

[2] Ferlay J, Shin HR, Bray F, et al. Estimates of worldwide burden of cancer in 2008: GLOBOCAN 2008. International Journal of Cancer 2010;127(12):2893917. 
[3] Iodice S, Maisonneuve P, Botteri E, et al. ABO blood group and cancer. European Journal of Cancer 2010;46(18):3345-50.

[4] Aird I, Bentall HH, Roberts JA. Relationship between cancer of stomach and the ABO blood groups. British Medical Journal 1953;1(4814):799-801.

[5] Milne RL, Osorio A, y Cajal RT, et al. Parity and the risk of breast and ovarian cancer in BRCA1 and BRCA2 mutation carriers. Breast Cancer Research and Treatment 2010;119(1):221-32.

[6] Hsieh CC, Trichopoulos D, Katsouyanni K, et al. Age at menarche, age at menopause, height and obesity as risk factors for breast cancer: associations and interactions in an international case-control study. International Journal of Cancer 1990;46(5):796-800.

[7] Kvåle G, Heuch I. Lactation and cancer risk: is there a relation specific to breast cancer? Journal of Epidemiology \& Community Health 1988;42(1):30-7.

[8] Dabelsteen E. Cell surface carbohydrates as prognostic markers in human carcinomas. The Journal of Pathology 1996;179(4):358-69.

[9] Hakomori SI. Tumor-associated carbohydrate antigens. Annual Review of Immunology 1984;2(1):103-26.

[10] Ichikawa D, Handa K, Hakomori SI. Histo-blood group A/B antigen deletion/reduction vs. continuous expression in human tumor cells as correlated with their malignancy. International Journal of Cancer 1998;76(2):284-9.

[11] Sleeman JP, Kim U, LePendu J, et al. Inhibition of MT450 rat mammary tumour growth by antibodies recognising subtypes of blood group antigen B. Oncogene 1999;18(31):4485-94.

[12] Aird I, Bentall HH, Mehigan JA, et al. The blood groups in relation to peptic ulceration and carcinoma of colon, rectum, breast and bronchus: an association between the $\mathrm{ABO}$ groups and peptic ulceration. British Medical Journal 1954;2(4883):315-21.

[13] Goldenberg IS, Hayes MA. Breast carcinoma and ABO blood groups. Cancer 1958;11(5):973-4.

[14] Mitra S, Mondal S, Basu A. The study of ABO blood groups in cancer of the female genital organs and cancer of the breast. Cancer 1962;15(1):39-41.

[15] Hartmann 0, Stavem P. ABO blood-groups and cancer. The Lancet 1964;283(7346):1305-6.

[16] Newell GR, Gordon JE, Monlezun AP, et al. ABO blood groups and cancer. Journal of the National Cancer Institute 1974;52(5):1425-30.

[17] Stamatakos M, Kontzoglou K, Safioleas P, et al. Breast cancer incidence in Greek women in relation to $\mathrm{ABO}$ blood groups and $\mathrm{Rh}$ factor. International Seminars in Surgical Oncology 2009;6(1):14.
[18] Majupuria KC, Gupta SR, Gupta LC. The study of ABO blood groups and relationship with cancer breast (a preliminary report). Indian Journal of Cancer 1966;3(3):182-3.

[19] Miao SY, Zhou W, Chen L, et al. Influence of ABO blood group and Rhesus factor on breast cancer risk: a meta-analysis of 9665 breast cancer patients and 244, 768 controls. Asia Pac Journal of Clinical Oncology 2014;10(2):101-8.

[20] Meo SA, Suraya F, Jamil B, et al. Association of ABO and $\mathrm{Rh}$ blood groups with breast cancer. Saudi Journal of Biological Sciences 2017;24(7):1609-13.

[21] Bhartiya SK, Dixit R, Vasanthan V, et al. Association of ABO blood group in breast cancer. International Journal of Biological and Medical Research 2015;6(3):5114-7.

[22] Anderson DE. Some characteristics of familial breast cancer. Cancer 1971;28(6):1500-4.

[23] Guleria K, Singh HP, Kaur H, et al. ABO blood groups in Gastrointestinal Tract (GIT) and breast carcinoma patients. The Anthropologist 2005;7(3):189-92.

[24] Mourali N, Muenz LR, Tabbane F, et al. Epidemiologic features of rapidly progressing breast cancer in Tunisia. Cancer 1980;46(12):2741-6.

[25] Amjadi 0, Rafiei A, Ajami A, et al. Blood groups: in health and diseases. Research in Molecular Medicine 2015;3(4):1-9.

[26] Garratty G. Blood groups and disease: a historical perspective. Transfusion Medicine Reviews 2000;14(4):291-301.

[27] Dede DS, Aksoy S, Dizdar 0, et al. Blood ABO groups and risk of breast cancer. Medical Oncology 2010;27(4):1433.

[28] Torti RA. ABO blood groups and Rh. antigens in patients with carcinoma of the breast. Medical Times 1963;91:1167-8.

[29] Surekha D, Shrinivasan A, Sailaja K, Rao D. Association of esterase $\mathrm{D}$ and $\mathrm{ABO}$ blood group in breast cancer. In: Trends in Human Genetics, Biotechnology and Bioinformatics: Next 5 years. 29th Annual conference of Indian Society of Human Genetics, Bangalore. 2004; 122-123.

[30] Hirohashi S. Tumor associated carbohydrate antigens related to blood group carbohydrates. GanTo Kagaku Rhyoho1986; 13(2): 1395-1401.

[31] Anderson DE, Haas C. Blood type A and familial breast cancer. Cancer Nov 1984; 14(9):1845-1849. 